\title{
Anthropological Engagements with Modern Psychotropy
}

\author{
Michael Oldani $\cdot$ Stefan Ecks $\cdot$ Soumita Basu
}

Published online: 12 April 2014

(C) Springer Science+Business Media New York 2014

The water from the tap. Of course...the group of so-called benighnimizers... Hedonidol, Euphoril... Empathan...[the government] put into the municipal water tower about 700 kilograms of bromo-benignimizer, mixing equal parts of Felicitine, Placidol and Superjubilan.

Stanislaw Lem, from The Futurological Congress, 1974:15, 29

Whether real or imagined, our world today seems saturated with psychiatric compounds. Stanislaw Lem's dark (and hilarious) opening pages in The Futurological Congress anticipate a world where drugs and their byproducts are literally in the water we drink. In Lem's vision designer drugs with neurological efficacydrugs that psychiatrists and the pharmaceutical industry call "psychotropics"- -are pumped into the water supply to subdue the unruly masses of an overpopulated world. His science fiction creates a time and place where innocent people are "psychotroped," induced into states of undirected joy and beatitude by drinking tap water. People can be also "troped" (p. 127) in the opposite direction, into darker moods and behaviors, by replacing an amino group with a hydroxyl, creating drugs like Antagonil, Sadistizine, and Furiol (p. 15).

In our current world, especially in the United States, we have entered into the era of science-fiction-meets-reality as people begin to be exposed to psychotropics on a daily basis in their urban water supplies. Psychiatric medications and other psychoactive compounds, such as prescription pain medications [e.g., the opiates, such as Vicodin (hydrocodone bitartrate and acetaminophen)] and sedatives as well

\footnotetext{
M. Oldani $(\bowtie)$

Department of Sociology, Anthropology and Criminal Justice, University of Wisconsin-Whitewater, Whitewater, WI, UK e-mail: oldanim@uww.edu

S. Ecks · S. Basu

Social Anthropology School of Social \& Political Sciences, University of Edinburgh, CMB, George Square, Edinburgh EH8 9LD, UK
} 
as illegal narcotics (e.g., cocaine), are now found in drinking water and fresh water lakes and rivers throughout the U.S. The data from metropolitan water departments in the United States are clear: we are increasingly drinking our drugs. The USA Today reported in 2008 through the Associated Press that a "vast array of pharmaceuticals-including antibiotics, anticonvulsants, mood stabilizers and sex hormones have been found in drinking water supplies of at least 41 million Americans." 1 Psychotropic concentrations in our water supplies fortunately remain minute. However, the types of compounds and their quantity are on the rise and the research regarding the collective effects of ingesting multiple kinds of pharmaceuticals over extended periods of time is in its infancy. Research has also shown that non-human species are at risk as well (Oldani, this volume), but the aqua-tropic impact on human minds and bodies is yet to be fully understood scientifically, nor has it been fully articulated for the general public. ${ }^{2}$

Within the pages of The Futurological Congress psychotropics are ubiquitous and mediate the individual and collective affect of human beings. Lem's vision of a pharmaceuticalized future is bleak or liberating depending on how you want to live out your final days on earth. Designer drug names reflect their efficacy: "Placidol" and "Superjubilan" are available formulations (Ibid: 29). Some readers of this Special Volume may also be familiar with fictional psychotropics brought to life on the Internet, such as Havidol (avafynetyem HCL) by the artist Justine Cooper in 2007. "The first and only treatment for dysphoric social attention consumption deficit anxiety disorder (DSACDAD)," Havidol remains a parody drug and an Internet hoax. Yet, initially "the drug" fooled a lot of medical consumers, who wandered into a New York art gallery wanting to know where they could find a prescription. ${ }^{3}$ These people seeking mental health treatment and/or wanting to be troped were turned away and undoubtedly had to settle for real psychotropics, such as Risperdol (risperidone), Zyprexa (olanzapine) or Lexapro (escitalopram). However, if they searched and shopped hard enough they actually could have found a prescription of "Abilify" (aripiprazole), which sounds very much like Havidol or Lem's Euphoril and could have easily been written into the pages of The Futurological Congress. Abilify, with a name that mirrors a desired outcome of pharmacological treatment, embodies its own marketing message and seems to have escaped regulatory naming scrutiny in the U.S. ${ }^{4}$ Abilify also continues to be part of

\footnotetext{
1 Reported on 3/10/2008, http://usatoday30.usatoday.com/news/nation/2008-03-10-cities-water_N.htm?csp= 34, accessed January 3, 2014 and on 3/12/2008, http://usatoday30.usatoday.com/news/nation/2008-03-10drugs-tap-water_N.htm, accessed March 10,2014. As both these articles note, in the U.S. local governments do not have to report on the psychotropic or prescription drug load present in drinking water. In fact, most modern filtration systems do not account for prescription drugs or their byproducts during the purification process.

2 Reported on 3/10/2008 ("Fish, wildlife affected by contaminated water"), http://usatoday30.usatoday. com/news/nation/2008-03-10-water-wildlife_N.htm, accessed March 18, 2014.

3 Reported on 2/16/07, http://www.reuters.com/article/2007/02/16/us-drug-fake-idUSL165119520070216, accessed March 10, 2014. Readers may also be familiar with the even more subversive "fukitol" as well (http:// www.fukitol.com/, access March 18, 2014 - thanks to Dehlia Hannah for this suggestion).

4 See the FDA document of drug name review procedures at http://www.fda.gov/downloads/Drugs/ DrugSafety/MedicationErrors/ucm080867.pdf, accessed December 3, 2013. For a fascinating discussion and historical perspective on (brand) naming American drugs, see Greene (2010).
} 
the top selling class of psychotropics, the atypical antipsychotics, with global sales peaking in 2008 at $\$ 22$ billion dollars. ${ }^{5}$

Janis Jenkins observes that, in North America, "the pharmaceutical imaginary has come to pervade subjectivity as the cultural and existential ground of everyday life" (2010, p. 8 17). Psychopharmaceuticals have seeped deep into both the ground water and into the popular imagination. The same cannot-yet-be said for the rest of the world. The usual explanation for this "treatment gap" between the awareness of psychopharmaceuticals in the US (and Europe) and other countries is that people outside the purview of biopsychiatry are less "educated" about the benefits of psychiatry; that they resort to an irrational stigmatization of psychotropic drugs; and that they have to suffer the consequences of inadequate funding of psychiatry in national and international health systems. All of this is certainly true, to some degree, but these explanations can leave out, or mask, key reasons for why these gaps persist. The papers in this special issue all provide ethnographic insights into emerging pharmaceutical imaginaries both in the US and beyond. Even in places like India, psychotropics are seeping in, to be drunk and to be eaten (see Ecks 2013; Ecks in this volume).

\section{Modern Psychotropy}

Perhaps it should come at no surprise that in the decades post-Prozac, there has occurred a blurring of fact and fiction within the discourse and practices of psychotropy. In particular, the pharmaceutical imaginary operates at precisely this kind of nexus: the interpellation of science and medicine, culture, capital, marketing, desire/fantasy, and human neuro-biologies (Jenkins 2010; Pinto, this volume). The drugs are "tropic" — that is, they are literally "turning"- both the self and society, making them sociotropic agents (Ecks 2005). These "tropic" psychoactive imaginaries and realities can quickly become toxic, even deadly. As this volume was taking shape, the American actor Phillip Seymour Hoffman was found dead in his apartment, killed by a "toxic mix" of psychotropics, which included, heroin, cocaine, amphetamines, and sedatives. ${ }^{6}$ Embodying psychotropic saturation and the perils of anomic showbiz, his death made international headlines, but human being are dying and suffering each day through similar, toxic psychotropic miscalculations. ${ }^{7}$ Sarah Pinto's work in this volume offers an

\footnotetext{
5 www.healthcarefinancenews.com/press-release/pipeline-antipsychotic-drugs-drive-next-market-evolution, accessed March 12, 2014.

6 www.cnn.com/2014/02/28/showbiz/philip-seymour-hoffman-autopsy/, accessed March 12, 2014.

7 The lines of use and abuse continue to be blurred in prescription-to-street drug use of opiates. For example, Oxycontin prescriptions often lead to abuse of heroin (see www.nytimes.com/2014/02/11/us/ heroins-small-town-too-and-a-mothers-pain.html, accessed February 12, 2014; also the Milwaukee Journal-Sentinel investigative series/watchdog report "Prescription for Tragedy," where $70 \%$ of the fatal overdoses in Milwaukee were due to a medical prescription, www.jsonline.com/watchdog/95915939, accessed March 10, 2014. There are emerging cases of overprescribing of stimulants (e.g., Ritalin [methyphenidate] to Vyvanse [lisdexamfetamine]) to treat ADHD (attention deficit/hyperactivity), where addiction and overdose become the tragic end result for young people (http://www.nytimes.com/2013/02/ 03/us/concerns-about-adhd-practices-and-amphetamine-addiction.html?_r=0, accessed February 2, 2014). These users often start either through legitimate diagnosis and medical prescriptions(s) or obtain
} 
ethnographic tracing of psychotropy, celebrity, and madness in India. She shows readers how the mixing of psychotropic prescribing, the surreal realities of celebrity, and mental illness treatment, can become toxic by masking other forms of violence, abuse, and trauma within highly vulnerable groups (e.g., single women in India). Collectively, these papers to varying degrees, demonstrate how the tropic effects of drugs are far from clear-cut and predictable, as both Rouse and Meyers discuss in this volume.

The conception of this special issue was partly inspired by an idea of "modern psychotropy" formulated by the historian, Smail (2008; see also Campbell et al. this volume). We borrowed this concept in order to expand the linkages, the multiple efficacies of, and the range of anthropological perspectives triggered by these compounds. Smail's On Deep History and the Brain argues that historical changes over the millennia were also changes of brain-body interactions. Anthropologists still work with a Boasian notion of a psychic unity of humankind, that places only culture in history but not the brain. Neurohistories, such as Smail's, troubles this assumption. And, given how deeply psychotropics have seeped in, it seems time for anthropologists to reconsider this position. Whether interpreted as medicinal, pathological, and/or addictive, psychotropics can now be obtained il/legally and have become another everyday "set of tools" (Rouse) for human being to modify or enhance their mood, emotional states, behavior, and social relations. We feel this Special Volume of Culture, Medicine, and Psychiatry builds upon previous collections concerned with psychopharmaceuticals (e.g., Elliot and Chambers 2004; Petryna et al. 2006, Chapters 1, 2, 3, 4 and 5; Kirmayer and Raikhel 2009; see also Williams et al. 2008 for sociological engagement with pharmaceuticals more generally and Dunbar et al. 2010 on drugs and addiction), while ethnographically and conceptually (re)engaging with new polypharmaceutical (Oldani) and psychotropic realities. For example, Meyers deals with the multiple efficacies of psychotropics within the complicated milieu of heroin addiction and the treatment of addicts with prescriptive compounds, such as Suboxone (buprenorphine $\mathrm{HCl}$ and naloxone $\mathrm{HCl}$ ). He not only explores both the "healing" and "poison" aspects of the pharmakon (opiate replacement therapy), but also conceptualizes how addicts come to "personify" this paradox of psychotropic efficacy and toxicity. By becoming the pharmakos, recovering addicts must embody "the lie" of their own treatment and possible recovery-a psychotropic tricking, or "lying to the brain" must occur through the body and through language.

Moreover, through these articles, we have sought to engage, complicate, and critique Smail's notion of modern psychotropy in more anthropological ways. Smail's neurohistory of humanity is somewhat ironic to us in that he seriously engages with, and excavates data from, all four subfields of anthropology. There are limitations to this approach, which Ben Campbell in his forward to this volume addresses, but Smail is successful in the sense that he is able to articulate over time

Footnote 7 continued

stimulants via illegal markets (i.e., social networks) and begin to use as "study drugs" (see http://www. nytimes.com/interactive/2012/06/10/education/stimulants-student-voices.html?ref=us, accessed February 12, 2014). 
and through space a narrative of human biocultural history that is both nuanced, broad, engaging, and thought-provoking. He also shares a kinship with the emergent field of neuroanthropology, with its emphasis on the enculturated brain and "plasticity" (Rees 2010; see also Oldani) as well interdisciplinary and biocultural approaches to inquiry and writing. Campbell, like us, also invites readers to engage with modern psychotropy through these articles in a way that envisions opportunities for more transdisciplinary and neuroanthropological futures, where collaboration between the sciences, the humanities, and the social sciences becomes more of a routine practice (e.g., Dressler et al. 2012; Lende 2012; Campbell and Garcia 2009). ${ }^{8}$

\section{Tropes and Psychotropics}

In Lem's fictional world, the government controls "the psychotropic load" (i.e., the efficacious concentration of drugs) emitted into the drinking water. In the everyday world(s) presented in these articles, drug companies, doctors, unlicensed prescribers, scientists, patients/medical consumers, family members, addicts, and drug dealers are the stakeholders that control the evaluation, prescribing, marketing, distribution, and ultimately, the consumption of psychotropics. Together, these papers trace, elaborate on, and problematize the cultural tropes and what might be called the key figures that have become at times synonymous, or at the very least, deeply involved with modern psychotropy: the deceitful addict; the recovering addict; the Alzheimer's patient; the worried well; disgraced celebrities (whether mentally ill or an addict or both); hysterical women; the high prescribing doctor; the quack; careerist researchers, and pharmaceutical salespersons (i.e., drug reps).

We feel these ethnographies provide opportunities to use psychotropy (and psychotropics) as a gateway into more fundamental issues of concern for medical anthropologists and other researchers. For example, Leibing shows how scientific and popular narratives for treating Alzheimer's patients continue to shift and evolve, starting in the 1990s, from brain-centered treatment with acetylcholine enhancers, to preventative treatments (i.e., slowing cognitive decline with the same set of psychotropics), to more holistic, bodily preventive measures, stressing cardiovascular risk-reduction with anti-diabetic medicines. And as Leibing outlines and Rouse discusses in her afterword, Big Pharma seems to recede into the background as one prescriptive narrative loses traction, only to regroup and resurface with new research and theories supporting use of psychotropics (even earlier) based on industry-produced assays and tests that detect specific "biomarkers" - a repurposing of countless pharmaceuticals, including psychotropics and cardiovascular medications has been envisaged and put into practice.

For Ecks, the prescribing of psychotropics in rural India by RMPs (unlicensed rural "quacks") provides an opportunity to assess larger, structural issues that make

\footnotetext{
8 Outside the realm of psychotropy, Anna Tsing's recent collaborations and creation of the "Matsutake Worlds Research Group" would be one type of transdisciplinary example of deep collaboration between the (social) sciences and humanities (see www.matsutakeworlds.org, accessed March 11 2014; see also Oldani this volume).
} 
these drugs "seep in" where no health planner expects them to even be present. Ecks' work demonstrates why RMPs are tolerated by the government to fill care gaps for the rural ill, and why they have become important prescribers of psychotropics. The RMPs are using psychotropics beyond the purview of either professional psychiatrists or any top-down health intervention. Easy access to drugs (including the likes of Prozac [fluoxetine]) allow unlicensed prescriptions to proliferate. Ecks also shows why RMPs are still cautious about using psychopharmaceuticals, not just because they see them as no more than short-term band aides for deeper, socioeconomic predicaments, but also because of unexpected conflicts within a highly complex pharmaceutical supply chain (see also Bartlett et al. 2014 for a critical review of treatment gaps, addiction and mental health.)

\section{Anthropological Phutures}

We are not the first to draw upon science fiction to help situate current scholarship regarding psychoactive drugs (see Kirmayer and Raikhel 2009; see also Haraway 1997). Nevertheless, The Futurological Congress is also a book about "a congress," an annual meeting of (drug hallucinating) academics no less! "Futurologists" have convened in Costa Rica to seriously discuss, assess and predict the future (and consequences) of human life on an overpopulated earth (Lem 1974, Chapter 1). This volume does not attempt to predict or speculate in detail on the psychotropic future of humans (and nonhumans). All that is clear is that the flow and circulation of modern psychotropics in all their various forms (e.g., prescribed, over-the-counter, branded, generic, and the illicit) will continue to enter ethnographically uncharted territories in years to come.

The contributions to this special issue, either directly or indirectly, are pointing our attention to particular saturation points of modern psychotropy, points that require further anthropological elaboration and critique. Addicts in recovery (Meyers), (pre)Alzheimer's patients (Leibing), single women and the rural poor in India (Pinto and Ecks, respectively), and the worried well in the U.S. (Oldani) share polypharmaceutical lifestyles and futures determined in large part by overprescribing, overuse, and overreliance of psychotropics. In the United States, still the epicenter of psychotropic science, marketing, and ab/use, clusters of strong resistance have emerged. And, it would of course be naïve not to acknowledge that there has always been cultural backlashes to psychotropy in both popular and academic forms. However, it is important to point out that some psychiatrists have also developed a more critical awareness of the overprescribing of psychotropics, a process of "pharmaceutical involution" (Oldani 2004) that they themselves helped to fuel during the last two decades. ${ }^{9}$ Some doctors now actively resist increasing the psychotropic load of their patients and engage in practices of psychotropic detox with both addictive

\footnotetext{
${ }^{9}$ Oldani (2004, pp. 339-353) pointed to the profitable outcomes of pharmaceutical involution (versus new drug innovation) within the context of overprescribing driven by the pharmaceutical sales tactics (e.g., gift exchanges) of drug reps. We now can see psychotropic involution through the saturation of bodies and populations: polypharmacy and/or overprescribing with very limited positive outcomes for patients (i.e., efficacy and toxicity without a cure).
} 
and non-addictive compounds (Oldani this volume). Research psychiatrists have also made proclamations, noting that we have entered "the end of the psychopharmacological revolution" (Tyrer 2012), not least in response to the devastating side effects that can occur with certain psychotropics (i.e., atypical antipsychotics). Data are available via recent clinical trials as well and show that no new and improved generation of psychotropics is on the horizon. And when even unlicensed prescribers in India are having misgivings about the efficacy of psychotropics (see Ecks), the golden era of these drugs seems to have truly come to an end.

Yet, at the same time, psychotropic polypharmacy continues to increase in children, women, addicts, and the elderly (see Pinto, Meyers and Oldani), while prescriptions in general are rising within emerging economies, as both Ecks and Pinto point out. Four decades of a US-centered "war on drugs" and almost thirty years after the introduction of Prozac in the US market, we seem to have entered a New World, Inc. (Haraway 1997), where psychotropics battle other psychotropics within the medical professions (see Ecks and Oldani), in the marketplace, and within our bodies, right down to the molecular level-battling for neuroreceptors (see Campbell). ${ }^{10}$ Within this context, new zones and sites of psychotropic saturation are surely to emerge, evolve, and take on unpredictable forms. Therefore, we encourage scholars to trace and assess modern psychotropy with creative tools of research-conceptual, anthropological, and/or interdisciplinary. Psychotropics will continue to seep deep into human, social, and natural environments, where their multiple efficacies and toxicities will require serious attention in order to fully evaluate their neuro-biological impact(s) and cultural power (see Rouse).

Acknowledgments We would like to thank all the contributors to this special issue, including the authors and specifically the commentators, Carolyn Rouse and Ben Campbell, for putting in the time and intellectual effort toward making this proposal a reality. We also would like to thank the editors at CMP, in particular Brandy Schillace, for their guidance and patience in helping to bring this Special Volume to fruition. Oldani would specifically like to thank the Center for twenty-first Century Studies at the University Wisconsin-Milwaukee for the space and resources to complete this project in 2013/14 as well as to specifically thank Merry Wiesner-Hanks for introducing him to Smail's Deep History during a past C21 fellowship in 2008/09. Ecks would like to thank Dominique Behague and Junko Kitanaka for organizing the invited panel Globalizing Biopsychiatry, Pharmaceuticalization, and the Interplay of Historical Contingencies, at the Annual Meeting of the American Anthropological Association at Montreal in 2011, which provided one of the jumping boards for this special issue.

\section{References}

Bartlett, N., W. Garriott, and E. Raikhel

2014 Ethnographic Perspectives on Addiction and Global Mental Health from China, Russia and the United States. Medical Anthropology: Cross-Cultural Studies in Health and Illness, doi:10.1080/ 01459740.2013.877900, accessed January 13, 2014.

Campbell, B., and J. Garcia

2009 Neuroanthropology: evolution and Emotional Embodiment. Frontiers in Evolutionary Neuroscience 1: 1-6.

\footnotetext{
${ }^{10}$ Haraway $(7,57)$ describes New World, Inc. in terms of both material and symbolic outcomes, where a retooling of organisms takes place-in the case of modern psychotropy, a merger, or interpellation, of nature, culture and the market occurs.
} 
Dressler, W.W., M.C. Balieiro, and J.E. dos Santos

2012 Cultural Consonance, Consciousness, and Depression: genetic Moderating Effects on the Psychological Mediators of Culture. In The Enculturated Brain: An Introduction to Neuroanthropology. D. Lende and G. Downey, eds., pp. 363-388. Boston: MIT Press.

Dunbar, D., H. Kushner, and S. Vrecko, eds.

2010 Drugs, Addiction and Society. BioSocieties 5(1): 2-7.

Ecks, S.

2005 Pharmaceutical Citizenship: antidepressant Marketing and the Promise of Demarginalization in India. Anthropology \& Medicine 12(3): 239-254.

2013 Eating Drugs: psychopharmaceutical Pluralism in India. New York: New York University Press.

Elliott, C., and T. Chambers, eds.

2004 Prozac as a Way of Life. Chapel Hill: North Carolina Press.

Greene, J.

2010 What's in a Name? Generics and the Persistence of the Pharmaceutical Brand in American Medicine. Journal of the History of Medicine and Allied Sciences 66(4): 468-506.

Haraway, D.

1997 Modest_Witness@Second_Millennium.FemaleMan`C_Meets_OncoMouse ${ }^{\mathrm{TM}}$ London: Routledge. Jenkins, J., ed.

2010 Pharmaceutical Self: the Global Sharping of Experience in an Age of Psychopharmacology. Santa Fe: School for Advanced Research Press.

Kirmayer, L. and E. Raikhel, eds.

2009 From Amrita to Substance D: psychopharmacology, Political Economy, and Technologies of the Self. Transcultural Psychiatry 46(1): 5-15.

Lem, S.

1974 The Futurological Congress (From the Memoirs of ljon Tichy). New York: The Seabury Press. Lende, D.

2012 Addiction and Neuroanthropology. In The Enculturated Brain: an Introduction to Neuroanthropology, D. Lende and G. Downey, eds., pp. 339-362. Boston: MIT Press.

Oldani, M.

2004 Thick Prescriptions: toward an Interpretation of Pharmaceutical Sales Practices. Medical Anthropology Quarterly 18(3): 25-56.

Petryna, A., A. Lakoff, and A. Kleinman, eds.

2006 Global Pharmaceuticals: ethics Markets, Practices. Durham: Duke University Press.

Rees, T.

2010 Being Neurologically Human Today: life and Science and Adult Cerebral Plasticity (an Ethical Analysis). American Ethnologist 37(1): 150-166.

Smail, D. L.

2008 On Deep History and the Brain. Berkeley: University of California Press.

Tyrer, $\mathrm{P}$.

2012 The End of the Psychopharmacological Revolution. The British Journal of Psychiatry 201(2): 168.

William, S., J. Gabe, and P. Davis, eds.

2008 The Sociology of Pharmaceuticals: progress and Prospects. Sociology of Health \& Illness 30(6): 813-824. 